\title{
Improved Trap Designs and Retention Mechanisms for Halyomorpha halys (Hemiptera: Pentatomidae)
}

\author{
Kevin B. Rice, ${ }^{1,6}$ William R. Morrison III, ${ }^{2}$ Brent D. Short, ${ }^{3}$ Angel Acebes-Doria, ${ }^{4}$ \\ J. Christopher Bergh, ${ }^{5}$ and Tracy C. Leskey ${ }^{3}$
}

\begin{abstract}
'Division of Plant Sciences, University of Missouri, 1-33 Agriculture Building, Columbia, M0 65211, 2USDA-ARS Center for Grain and Animal Health Research, Manhattan, KS 66502, ${ }^{3}$ USDA-ARS Appalachian Fruit Research Station, Kearneysville, WV 25430, ${ }^{4}$ Department of Entomology, University of Georgia - Tifton, Tifton, GA 31794, ${ }^{5}$ Virginia Tech, Alson H. Smith, Jr. Agricultural Research and Extension Center, Winchester, VA 22602, and ${ }^{6}$ Corresponding author, e-mail: ricekev@missouri.edu
\end{abstract}

Subject Editor: Charles Burks

Received 27 March 2018; Editorial decision 9 June 2018

\begin{abstract}
Current monitoring systems for the invasive Halyomorpha halys (Stål) (Hemiptera; Pentatomidae) in orchard agroecosystems rely on ground-deployed tall black pyramid traps baited with the two-component $H$. halys aggregation pheromone and pheromone synergist. Pyramid traps are comparatively costly, require considerable time to deploy and service, and may not be best suited to grower needs. Therefore, we evaluated other traps for H. halys, including modified pyramid traps (lures deployed on the outside), a canopy-deployed small pyramid, a pipe trap, delta traps, and yellow sticky cards in 2015 and 2016 in commercial apple and peach orchards. We also compared various $H$. halys killing agents for use in standard pyramid trap collection jars, including VaporTape kill strips, cattle ear tags, and plastic netting treated with various pyrethroids. Finally, we evaluated the effect of positioning the lures inside versus outside the collection jar on standard pyramid traps on overall captures. Among trap types, modified pyramid and pipe traps were most effective, capturing more adults than all other trap designs. Adult captures in small canopy-deployed pyramid, delta, and yellow sticky traps were lower, but significantly correlated with the standard black pyramid. Placing lures on the outside of collection jars on pyramid traps resulted in significantly greater captures and insecticide-impregnated netting was as effective for retaining bugs as VaporTape strips. These studies demonstrate that trapping systems for $H$. halys can be simplified and improved by modifying the trap design, lure deployment location, and/or killing agent.
\end{abstract}

Keywords: BMSB, brown marmorated stink bug, monitoring, integrated pest management

Effective monitoring tools for insect pests are an essential component of integrated pest management (IPM). Efficient traps can support management decisions such as timing of insecticide applications based on captures, thereby reducing production costs, nontarget effects, and secondary pest outbreaks (Toscano et al. 1974, Ragsdale et al. 2007). Invasive insect species can severely disrupt established IPM programs (Szczepaniec et al. 2011, Leskey et al. 2012b), and can be particularly difficult to monitor because of general lack of knowledge about their behavior and ecology in the invaded range (Elton 1958, Lockwood et al. 2013).

Halyomorpha halys (Stål) (Hemiptera; Pentatomidae) is an invasive herbivore originating from Asia that currently has established populations in the United States, Canada, Western and Eastern Europe, and South America (Hoebeke and Carter 2003, Wermelinger et al. 2008, Gariepy et al. 2014, Faúndez and Rider 2017, Leskey and Nielsen 2018). H. halys is a major agricultural pest of a wide range of commodities including fruits, vegetables, field crops, and ornamentals, and has caused severe economic injury (American Western Fruit Grower 2011, Rice et al. 2014, Leskey and Nielsen 2018). In response, growers have relied on weekly insecticide applications, leading to increased production costs and secondary pest outbreaks (Leskey et al. 2012b).

In Asia, stink bug monitoring programs suggested that $H$. halys were cross-attracted to the aggregation pheromone of the oriental stink bug Plautia stali Scott (Hemiptera; Pentatomidae), methyl (2E,4E,6Z)-2,4,6-decatrienoate (MDT) (Tada et al. 2001a,b; Lee et al. 2002). This was confirmed later with invasive $H$. halys populations in the United States (Aldrich et al. 2007, Khrimian et al. 2008). In 2014, the two-component aggregation pheromone of $H$. halys was identified as $(3 S, 6 S, 7 R, 10 S)$-10,11-epoxy-1-bisabolen-3-ol and (3R,6S,7R,10S)-10,11-epoxy-1-bisabolen 3-ol (PHER) (Khrimian et al. 2014). When deployed with visually attractive black pyramid 
traps (Leskey et al. 2012a), PHER and MDT provided effective season-long monitoring of $H$. halys adults and nymphs (Weber et al. 2014, Leskey et al. 2015, Morrison et al. 2015). These pyramid traps have been used as a decision support tool in apple orchards (Short et al. 2017) but are large, expensive, require considerable labor to deploy and service, and can interfere with farm operations such as chemical applications and mowing. Additionally, its collection jar requires venting modifications (Leskey and Hogmire 2005) and a killing mechanism such as 2,2-dichlorovinyl dimethyl phosphate (DDVP) VaporTape strips to prevent $H$. halys escape, adding additional costs and labor. In Asia, yellow sticky traps baited with pheromone lures are used to monitor P. stali (Toyama et al. 2015), although this trap had not been evaluated for $H$. halys.

The goals of this study were to refine $H$. halys trapping techniques to reduce costs and labor associated with trapping systems for $H$. halys. First, we evaluated $H$. halys captures in standard pyramid traps with five other trap designs that were either commercially available, less expensive, and/or potentially easier to deploy. We then evaluated five different $H$. halys killing mechanisms for use in collection jars atop the standard black pyramid traps, as well as the efficacy insecticide-treated netting. Finally, we compared the effect of lure positioning on captures in pyramid traps.

\section{Methods}

\section{Trap Type}

We evaluated $H$. halys adult and nymphal captures in the following traps (Fig. 1) deployed in commercial orchards: 1) standard black Coroplast pyramid traps (Dead-Inn Pyramid Trap, $1.2 \mathrm{~m}$ height, AgBio Inc., Westminster, $\mathrm{CO})$; 2) experimental pipe traps $(1.2 \mathrm{~m}$ height); 3) modified black Coroplast pyramid traps (Dead-Inn Pyramid Trap, $1.2 \mathrm{~m}$ height, AgBio Inc); 4) smaller black pyramid traps (Dead-Inn Pyramid Trap, $0.29 \mathrm{~m}$ height, AgBio Inc.); 5) yellow back-folding sticky cards $(23 \times 14 \mathrm{~cm}$, Alpha Scents, West Linn, OR); and 6) orange delta traps (Pherocon VI Delta, Trece Inc. Adair, OK). Each trap was baited with a lure containing PHER (10 mg) and MDT (66 mg) (AgBio, Inc.). Lures were positioned above delta and sticky traps by attaching them to hanging wires with binder clips. Standard pyramid, small pyramid, and pipe traps had lures and $5 \mathrm{~cm}$ pieces of DDVP kill strips (Hercon VaporTape II, Hercon Environmental, Emigsville, PA) inside the vented collection jar (Joseph et al. 2013). Kill strips were replaced every other week. Standard pyramid traps consisted of Coroplast panels $(1.07 \mathrm{~m}$ in height, $52 \mathrm{~cm}$ width at the base, $8.2 \mathrm{~cm}$ width at the top) topped with a clear plastic collection jar $(16 \times 10 \times 10 \mathrm{~cm} \mathrm{H}$ :L:W $)$ with an inverted funnel cone lid (1.6 cm internal opening) (AgBio, Inc., Westminster, CO). Collection jars were vented on all four sides with $3 \mathrm{~cm}$ openings covered with vinyl-coated polyester screen (mesh size: $1 \times 3 \mathrm{~mm}^{2}$ ).

The modified pyramid trap consisted of an unvented collection jar with lures attached to the outside top of the jar, and netting treated with $25 \% \mathrm{v} / \mathrm{v}$ lambda-cyhalothrin (a.i 22.8\%) (Quest Outfitters, Sarasota, FL, No-See-Um-Mesh) attached to the inside funnel $\left(\sim 250 \mathrm{~cm}^{2}\right)$ as a replacement for VaporTape kill strips. Mesh netting was soaked in insecticide solution for $1 \mathrm{~h}$, and then air-dried for $24 \mathrm{~h}$ in a fume hood. Nets were cut to cover to the entire surface area of the inside funnel of jar tops of pyramid traps and attached with glue. Pipe trap bases were constructed from $81 \mathrm{~cm}$ long PVC pipe (10 cm diameter), painted canary yellow (Rust-Oleum, Vernon Hills, IL) and wrapped with black charcoal fiberglass insect screen (18 threads $/ 2.5 \mathrm{~cm}$ ) (Saint-Gobain ADFORS, Malvern, PA) (Jasinski and Welty, personal communication).

Standard and modified pyramid traps were deployed on the ground between trees in the border row or at row ends. Pipe bases were placed over a $0.91 \mathrm{~m}$ fence post that was staked into the ground and also deployed between trees or at the row ends. Smaller pyramid (see Morrison et al. 2015), delta, and sticky traps were deployed on scaffold limbs in the tree canopy (see Morrison et al. 2015) while delta and sticky traps were hung from scaffold limbs in the tree canopy. In 2015, traps were deployed from 27 May through 28 September at five commercial apple orchards and from 20 April through 30 September at three commercial peach orchards (see Table 1 for locations). In 2016, traps were deployed from 3 May through 11 October at three commercial apple orchards and from 3 May through 13 September at two commercial peach orchards. Three replicates of each trap per site were positioned randomly at $50 \mathrm{~m}$ intervals along orchard edges adjacent to woods. Year and orchard type (apple or peach) were analyzed separately, because preliminary models showed significant differences in abundance of $H$. halys. Total season long captures of $H$. halys adult and nymphs were compared among trap types using a generalized linear model with repeated measures by time. The model used a quasi-poisson distribution to account for overdispersion in the data set and appropriately adjust standard error values (Aho 2014). Tests for significance employed log-likelihood ratio tests based on a $\chi^{2}$-distribution. Upon a significant result from the model, pairwise comparisons employed Tukey's honest significant difference (HSD). Afterward, standard black pyramid trap captures were compared with other trap types

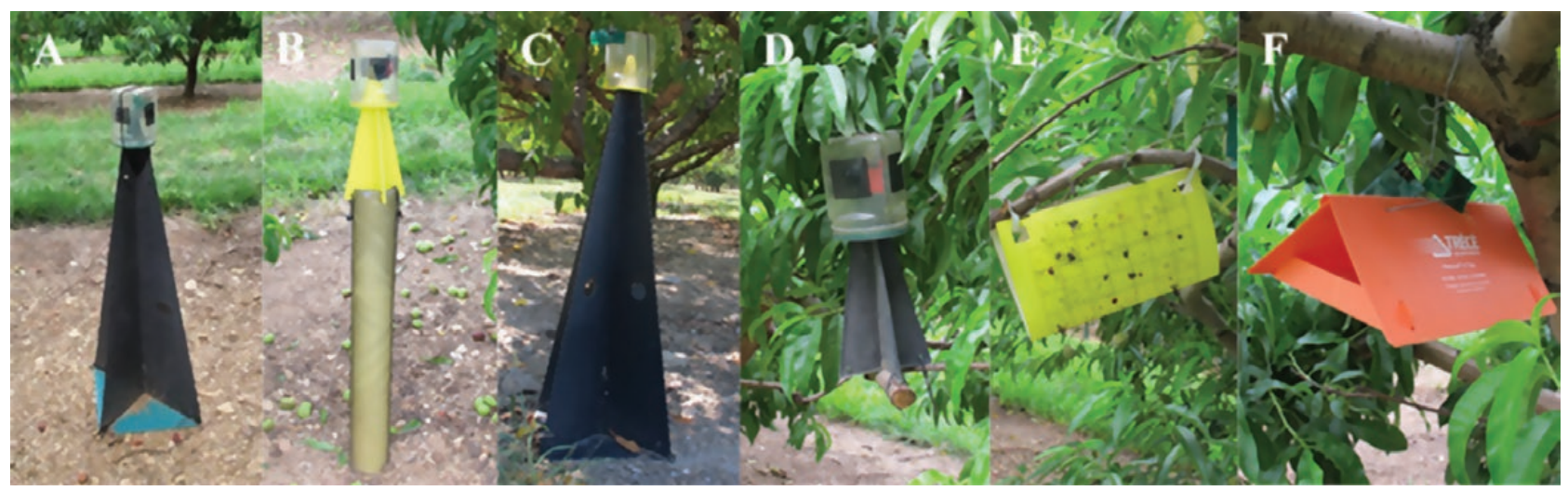

Fig. 1. Trap types used to capture adult and nymphal $H$. halys captures: A) standard black pyramid, B) pipe, C) modified pyramid, D) small hanging pyramid, E) yellow sticky, and F) orange delta trap. 
Table 1. Location and GPS coordinates of field sites comparing Halyomorpha halys captures among different trap types

\begin{tabular}{lcccr}
\hline Location (Co., State) & Year & Crop & Latitude & Longitude \\
\hline Berkeley, WV & $2015-2016$ & Peach and Apple & $39^{\circ} 27^{\prime} 14.53^{\prime \prime} \mathrm{N}$ & $78^{\circ} 2^{\prime} 7.12^{\prime \prime} \mathrm{W}$ \\
Berkeley, WV & $2015-2016$ & Apple & $39^{\circ} 23^{\prime} 38.38^{\prime \prime} \mathrm{N}$ & $78^{\circ} 44^{\prime} 47.99^{\prime \prime} \mathrm{W}$ \\
Jefferson, WV & 2015 & Apple & $39^{\circ} 22^{\prime} 25.59^{\prime \prime} \mathrm{N}$ & $77^{\circ} 51^{\prime} 57.07^{\prime \prime} \mathrm{W}$ \\
Washington, MD & 2015 & Apple & $39^{\circ} 40^{\prime} 25.20^{\prime \prime} \mathrm{N}$ & $77^{\circ} 32^{\prime} 25.80^{\prime \prime} \mathrm{W}$ \\
Washington, MD & $2015-2016$ & Peach & $39^{\circ} 39^{\prime} 32.20^{\prime \prime} \mathrm{N}$ & $77^{\circ} 33^{\prime} 16.86^{\prime \prime} \mathrm{W}$ \\
Frederick, VA & 2016 & Apple & $39^{\circ} 6^{\prime} 12.16^{\prime \prime} \mathrm{N}$ & $78^{\circ} 17^{\prime} 18.63^{\prime \prime} \mathrm{W}$ \\
Cecil, MD & 2015 & Apple & $39^{\circ} 40^{\prime} 29.38^{\prime \prime} \mathrm{N}$ & $75^{\circ} 49^{\prime} 28.44^{\prime \prime} \mathrm{W}$ \\
Carroll, MD & 2015 & Peach & $39^{\circ} 36^{\prime} 36.57^{\prime \prime} \mathrm{N}$ & $77^{\circ} 3^{\prime} 14.28^{\prime \prime} \mathrm{W}$ \\
\hline
\end{tabular}

using Pearson's correlation to understand if the phenological information about captures in the other trap types was similar to that from standard black pyramid traps.

\section{Killing Agents}

We compared the efficacy of the following retention/killing mechanisms for $H$. halys adults and nymphs in standard black pyramid traps: 1) cattle ear tags (Python Magnum, Southern States, Richmond, VA); 2) insecticide netting (Quest Outfitters, Sarasota, FL, No-See-Um-Mesh) (a.i. 22.8\% lambda-cyhalothrin soaked for $18 \mathrm{~h}$ ); 3) insecticide netting (a.i 22.8\% lambda-cyhalothrin treatment soaked for $1 \mathrm{~h}) ; 4$ ) VaporTape kill strips replaced every two weeks (Hercon Environmental, Emigsville, PA); 5) VaporTape kill strips with no replacement; and 6) control (no killing mechanism). VaporTape kill strips (a.i. = dichlorovinyl) were cut in half and ear tags (a.i. = zeta-cypermethrin) were cut to have equal surface area as kills strips, both of these were hung from the inside top of collection jars. All traps were baited with PHER and MDT lures. In 2014, three replicates of traps were deployed from 18 July through 3 October, along the edges of orchards and wood lines and spaced 50 $\mathrm{m}$ apart at the Appalachian Fruit Research Station in Kearneysville, WV. Treatment location was randomized each week. Traps were emptied each week and the number of live and dead $H$. halys adults and nymphs recorded. The effectiveness of each killing mechanism was compared using five separate repeated measure analysis of variance (ANOVA), with total $H$. halys captured, dead adults, live adults, dead nymphs, or live nymphs as the response variable. Dead nymphs and total $H$. halys captures were cube-root transformed to meet the normality assumption. Explanatory variables for each model included killing mechanism, replication, and week. Pairwise comparisons were analyzed using Tukey's HSD when ANOVA was significant.

We examined the efficacy of netting (Trimaco, Morrisville, NC) (see Trap Type for details) treated with the following pyrethroids to retain and kill $H$. halys in black pyramid traps (see Table 5 for details): 1) lambda-cyhalothrin (25\% V/V; 2) zeta-cypermethrin and bifenthrin $(10 \% \mathrm{~V} / \mathrm{V}) ; 3)$ zeta-cypermethrin and bifenthrin $(25 \%$ $\mathrm{V} / \mathrm{V})$; 4) pyrethrins ( $25 \% \mathrm{~V} / \mathrm{V})$; and 5 ) untreated control. Traps were baited with PHER (10 mg) and MDT (66 mg) and deployed along orchard and wood line edges at the Appalachian Fruit Research Station in Kearneysville, WV from 2 September through 22 October 2016. Each location contained three replicates, and traps were spaced $50 \mathrm{~m}$ apart. The locations of treatments were randomized each week. Traps were emptied each week and the number of live and dead $H$. halys nymphs and adults recorded. To compare the effectiveness of each insecticide-treated net, adult and nymphal captures were evaluated with four separate repeated measure ANOVA with dead adults, live adults, dead nymphs, or live nymphs as the response variable. Dead adults were cube-root transformed to meet the normality assumption. Explanatory variables for each model included insecticide, replication, and week. Pairwise comparisons were analyzed using Tukey's HSD when ANOVA was significant.

\section{Lure Position}

We compared $H$. halys captures in standard pyramid traps with lures deployed in the following positions: 1 ) hanging from inside the vented collection jar (standard position); 2) hanging from the outside middle of collection jar; and 3) hanging from the pyramid base, $30 \mathrm{~cm}$ below the bottom of collection jars. Traps were spaced $50 \mathrm{~m}$ apart along orchards and wood lines from 13 September through 27 September 2013. VaporTape kill strips were replaced every other week. Traps were emptied each week and the number of $H$. halys were compared using ANOVA. All statistical analyses were conducted using SAS (SAS 2004).

\section{Results}

\section{Trap Type}

Total H. halys captures in apple orchards in 2015 and 2016, respectively, were 1,991 nymphs and 3,298 adults, and 3,492 nymphs and 5,378 adults. In 2015, modified pyramid traps captured significantly more adult $H$. halys $\left(\chi^{2}=214.4 ; \mathrm{df}=5 ; P<0.0001\right)$ and pipe traps $\left(\chi^{2}=325.7 ; \mathrm{df}=5 ; P<0.0001\right)$ captured significantly more nymphs compared with standard pyramid, small pyramid, yellow sticky cards and delta traps (Fig. 2). In 2016, modified pyramid traps again captured more adults compared with all other traps except pipe traps $\left(\chi^{2}=384.3 ; \mathrm{df}=5 ; P<0.0001\right)$; modified pyramid, pipe, small pyramid, and standard pyramids traps captured significantly greater numbers of nymphs compared with yellow sticky and delta traps $\left(\chi^{2}=174.0 ; \mathrm{df}=5 ; P<0.0001\right)$ (Fig. 2$)$. In both years, adult captures in standard pyramid traps were significantly correlated with adult captures in all other trap types, and nymphal captures in standard pyramid traps were correlated with captures in all other traps except yellow sticky traps in 2015 and delta traps in 2016 (Table 2).

In peach orchards during 2015 and 2016, respectively, combined captures totaled 153 nymphs and 435 adults, and 829 nymphs and 1,080 adults. In 2015, modified pyramid and pipe traps captured significantly more adults than all other trap types $\left(\chi^{2}=241.8\right.$; $\mathrm{df}=5$; $P<0.0001)$, and pipe traps captured significantly more nymphs compared with all traps except modified pyramids $\left(\chi^{2}=261.7 ; \mathrm{df}=5\right.$; $P<0.0001)$. In 2016, modified pyramids captured greater numbers of adults $\left(\chi^{2}=188.6 ; \mathrm{df}=5 ; P<0.000\right)$ and nymphs $\left(\chi^{2}=120.2\right.$; $\mathrm{df}=5 ; P<0.0001)$ compared with small pyramid, yellow sticky, and delta traps (Fig. 3). Adult captures in standard pyramid traps were correlated with all other trap types except for delta traps in 2016. For nymphs, captures in standard pyramid traps were correlated with small and modified pyramid traps in both years and with yellow sticky traps and pipe traps in 2015 and 2016, respectively (Table 3). 


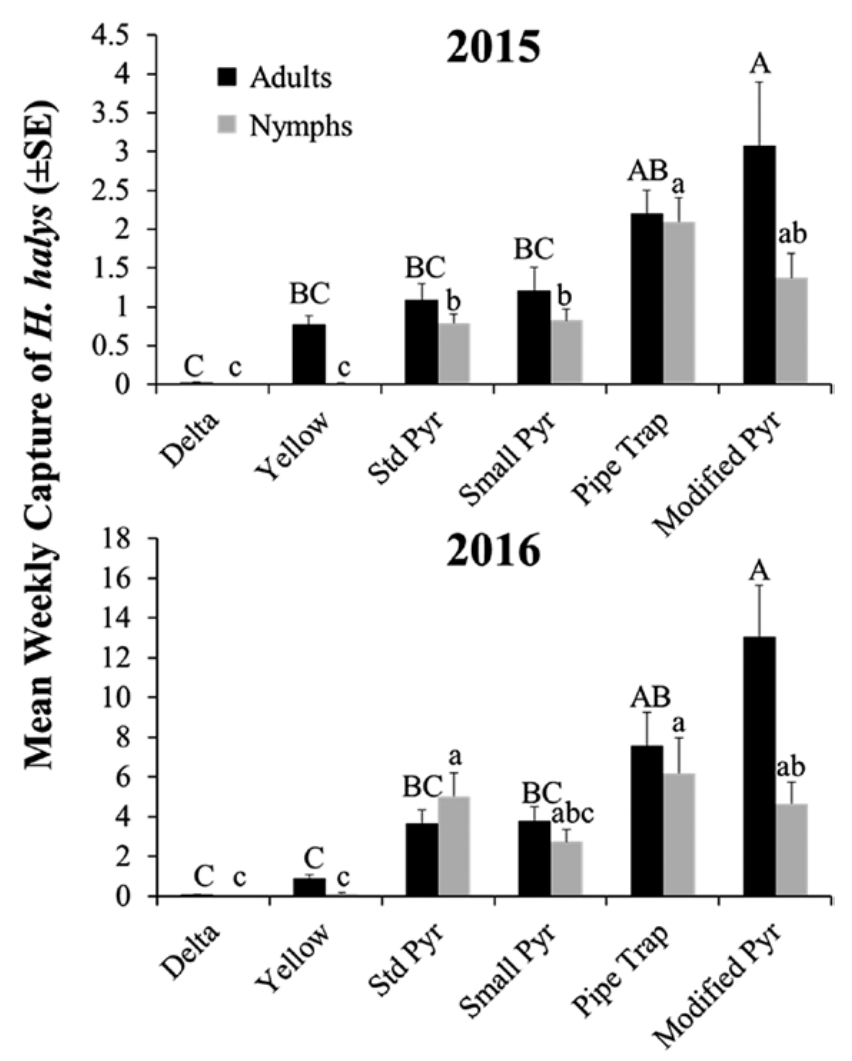

Trap Type

Fig. 2. Mean weekly adult and nymphal $H$. halys captures by trap type in apple orchards in 2015 and 2016. Capitalized letters represent pairwise comparisons among adult captures, while lower case letters represent pairwise comparisons among nymphal captures. Bars with shared letters are not significantly different from each other ( $\alpha=0.05$, Tukey's HSD).

Table 2. Pearson correlation coefficient between captures of $H$. halys in standard black pyramid traps and other traps in apple orchards in 2015 and 2016

\begin{tabular}{|c|c|c|c|c|c|c|c|}
\hline \multirow[b]{2}{*}{ Trap type } & \multicolumn{4}{|c|}{ Adults } & \multicolumn{3}{|c|}{ Nymphs } \\
\hline & $r$ & $\mathrm{df}$ & $t$ & $P$ & $R$ & $t$ & $P$ \\
\hline \multicolumn{8}{|l|}{2015} \\
\hline Yellow Sticky Card & 0.732 & 132 & 12.4 & $* * *$ & 0.054 & 0.6 & ns \\
\hline Modified Pyramid & 0.759 & 132 & 13.4 & $* * *$ & 0.586 & 8.3 & $* * *$ \\
\hline Pipe Trap & 0.858 & 132 & 19.2 & $* * *$ & 0.813 & 16.0 & $* *$ \\
\hline Small Pyramid & 0.729 & 132 & 12.2 & $* * *$ & 0.670 & 10.4 & $* *$ \\
\hline Delta Trap & 0.266 & 132 & 3.2 & $* *$ & 0.440 & 5.6 & $* * *$ \\
\hline \multicolumn{8}{|l|}{2016} \\
\hline Yellow Sticky Card & 0.447 & 64 & 4.0 & $* * *$ & 0.463 & 4.2 & $* *$ \\
\hline Modified Pyramid & 0.626 & 64 & 6.4 & $* * *$ & 0.857 & 13.3 & $* *$ \\
\hline Pipe Trap & 0.411 & 64 & 3.6 & $* *$ & 0.582 & 5.7 & $* *$ \\
\hline Small Pyramid & 0.477 & 64 & 4.3 & $* * *$ & 0.852 & 13.0 & $* *$ \\
\hline Delta Trap & 0.329 & 64 & 2.8 & $* *$ & 0.160 & 1.3 & ns \\
\hline
\end{tabular}

ns $=$ not significant $(P>0.05),{ }^{*} P<0.05,{ }^{*} P<0.01,{ }^{* * *} P<0.001$.

\section{Killing Agent}

Traps with ear tags yielded significantly greater total captures of $H$. halys compared with control traps and kill strip augmented traps that were not replaced following deployment $(F=3.44$; $\mathrm{df}=5,206$; $P=0.005)$. Traps containing insecticide netting $(18 \mathrm{~h}$ treatment $)$ and

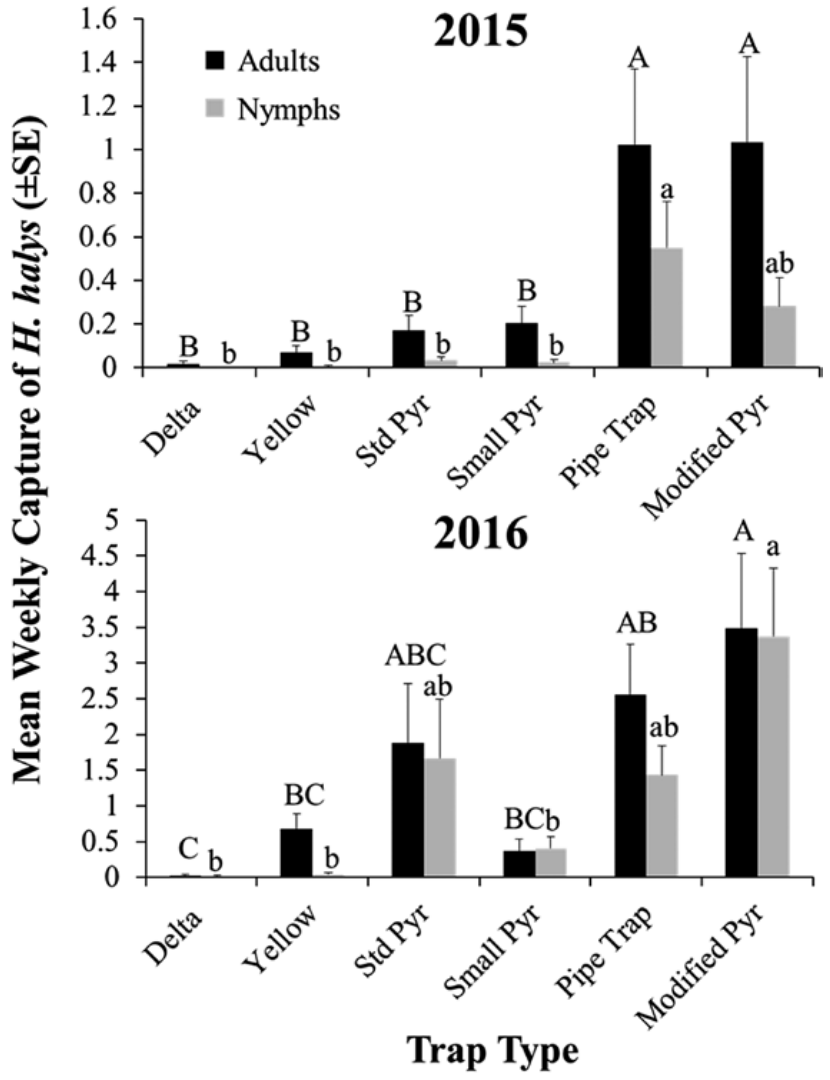

Fig. 3. Mean weekly adult and nymph $H$. halys captures by trap type in peach orchards in 2015 and 2016. Capitalized letters represented pairwise comparisons among adult captures, while lower case letters represent pairwise comparisons among nymphal captures. Bars with shared letters are not significantly different from each other ( $\alpha=0.05$, Tukey's HSD).

Table 3. Pearson correlation coefficient between captures of $H$. halys in standard black pyramid traps and the following traps in peach orchards in 2015 and 2016

\begin{tabular}{|c|c|c|c|c|c|c|c|}
\hline \multirow[b]{2}{*}{ Trap type } & \multicolumn{4}{|c|}{ Adults } & \multicolumn{3}{|c|}{ Nymphs } \\
\hline & $r$ & $\mathrm{df}$ & $t$ & $P$ & $R$ & $t$ & $P$ \\
\hline \multicolumn{8}{|l|}{2015} \\
\hline Yellow Sticky Card & 0.745 & 60 & 8.7 & $* * *$ & 0.333 & 2.7 & $* *$ \\
\hline Modified Pyramid & 0.881 & 60 & 14.4 & $* * *$ & 0.363 & 3.0 & $* *$ \\
\hline Pipe Trap & 0.950 & 60 & 23.6 & $* * *$ & 0.157 & 1.2 & ns \\
\hline Small Pyramid & 0.722 & 60 & 8.1 & $* * *$ & 0.424 & 3.6 & $* *$ \\
\hline Delta Trap & 0.040 & 60 & 0.3 & ns & $a_{-}$ & - & - \\
\hline \multicolumn{8}{|l|}{2016} \\
\hline Yellow Sticky Card & 0.556 & 40 & 4.2 & $* *$ & 0.295 & 2.0 & ns \\
\hline Modified Pyramid & 0.587 & 40 & 4.6 & $* * *$ & 0.753 & 7.2 & $* * *$ \\
\hline Pipe Trap & 0.929 & 40 & 15.9 & $* * *$ & 0.850 & 10.2 & $* * *$ \\
\hline Small Pyramid & 0.591 & 40 & 4.6 & $* * *$ & 0.587 & 4.6 & $* * *$ \\
\hline Delta Trap & 0.316 & 40 & 2.1 & $*$ & 0.028 & 0.2 & ns \\
\hline
\end{tabular}

ns $=$ not significant $(P>0.05), * P<0.05, * * P<0.01, * * P<0.001$.

${ }^{a}$ Test not possible because of no captures of nymphs in the delta traps during the season.

ear tags yielded greater numbers of dead adults compared with control traps $(F=4.13$; df $=5,206 ; P=0.0014)$. However, traps with ear tags had similar numbers of live adults as control traps, whereas traps with insecticidal netting and kill strips that were replaced every 
two weeks yielded significantly fewer live adults compared with control traps $(F=11.93 ; \mathrm{df}=5,206 ; P<0.0001)$ (Table 4). Traps with insecticidal netting (both $18 \mathrm{~h}$ and $1 \mathrm{~h}$ treatments) contained significantly greater numbers of dead nymphs compared with control traps $(F=5.77 ; \mathrm{df}=5,206 ; P<0.0001)$. The overall number of live nymphs in traps was low (190 individuals), therefore statistical analysis was not conducted.

Traps containing netting treated with lambda-cyhalothrin yielded significantly greater numbers of dead $H$. halys adults compared with control traps $(F=3.1 ; \mathrm{df}=4,120 ; P=0.016)$, and those with netting treated with lambda-cyhalothrin, or zeta-cypermethrin and bifenthrin (both 10 and $25 \% \mathrm{~V} / \mathrm{V}$ ) had fewer live adults compared with traps containing pyrethrin-treated nets or controls $(F=6.22 ; \mathrm{df}=4$, $120 ; P=0.0002$ ) (Table 5). No statistical difference was observed among insecticide treated nets for live nymphs. Only two dead nymphs were recorded across all treatments; therefore, no statistical analyses were performed on dead nymphs.

\section{Lure Position}

Greater numbers of bugs were captured when lures were placed on the outside of jar tops compared with lures placed inside of jar tops $(F=5.14 ; \mathrm{df}=2,24 ; P=0.015)$, and captures for lures placed high and low on outside of traps were not statistically different (Fig. 4).

\section{Discussion}

We have demonstrated varying effectiveness of different styles of monitoring traps for $H$. halys. Although several monitoring and detection devices have been developed for $H$. halys (Leskey et al. 2012a,b; Nielsen et al. 2013; Rice et al. 2015), ground-deployed standard black pyramid traps are considered the most sensitive, providing season-long captures of adults and nymphs (Joseph et al. 2013, Morrison et al. 2015), but are more costly than other commercially available traps. Replacing pyramid traps with simpler, less expensive traps may increase adoption of $H$. halys monitoring, thus potentially reducing nontarget effects and secondary pest outbreaks associated with calendar-based insecticide applications (Rice et al.
2015). Although sticky traps deployed in trees captured significantly fewer $H$. halys compared with ground-deployed modified pyramid and pipe traps, adult captures in both years and nymphal captures in 2016 were correlated with standard pyramid traps in both apple and peach orchards, suggesting these traps may adequately predict relative $H$. halys presence, abundance, and seasonal activity, while requiring less effort to enumerate individuals on traps. Moreover, a recent study by Morrison et al. (2017a) used clear sticky traps deployed on wooden posts and baited with PHER + MDT to monitor $H$. halys populations in the eastern United States and in multiple European countries, although how these captures relate to those of standard pyramid traps is unknown. Deploying sticky traps attached atop wooden posts on the ground might reduce the number of structures by which foraging $H$. halys become arrested on, compared to the numerous and complex branching structures found within tree canopies (as we report here) (Leskey and Nielsen 2018). Thus, ground-deployed trap designs could be most sensitive for $H$. halys mobile life stages due to fewer options for foraging individuals to become arrested by pheromonal stimuli. Captures in grounddeployed pyramid traps baited with PHER + MDT combination were used as decision support tools for $H$. halys in apple orchards, with insecticides applied only when a predetermined cumulative adult captures in traps were reached (Short et al. 2017). Thus, to move to simpler designs, further studies that compare alternate trap designs with the widely used standard pyramid trap, under varying population densities, must be conducted.

A killing agent is necessary for successful trapping of $H$. halys using pyramid traps with collection jars, as Leskey et al. (2012a) found a 250-fold increase in trap captures when a killing agent was added. This is quite different than native stink bugs such as Euschistus servus Say (Hemiptera; Pentatomidae), which can be contained within collection jars in the absence of a killing agent by simple mechanical modifications to the collection jar (Hogmire and Leskey 2006). The strong mobility of both adult and nymphal H. halys (Lee et al. 2014, Lee and Leskey 2015) may account for these differences. In our studies, insecticide netting outperformed all other insecticide-based killing mechanisms including DDVP strips and cattle ear tags, having the greatest number of dead bugs and lowest number of live bugs

Table 4. Comparison of $H$. halys kill mechanisms in standard black pyramid traps

\begin{tabular}{|c|c|c|c|c|c|c|}
\hline Kill mechanism & Active ingredient & Total capture & Dead adults & Live adults & Dead nymphs & Live nymphs \\
\hline Ear Tag & Zeta-cypermethrin & $95.8 \pm 18.6 \mathrm{~A}$ & $63.5 \pm 15.3 \mathrm{~A}$ & $12.5 \pm 3.5 \mathrm{AB}$ & $17.5 \pm 5.2 \mathrm{ABC}$ & $2.2 \pm 0.7 \mathrm{AB}$ \\
\hline Net $(18 \mathrm{~h})$ & Lambda-cyhalothrin & $73.4 \pm 12.8 \mathrm{AB}$ & $51.8 \pm 10.3 \mathrm{AB}$ & $0.06 \pm 0.1 \mathrm{~B}$ & $21.5 \pm 5.8 \mathrm{AB}$ & $0.0 \pm 0.0 \mathrm{C}$ \\
\hline Net $(1 \mathrm{~h})$ & Lambda-cyhalothrin & $83.0 \pm 17.5 \mathrm{AB}$ & $51.5 \pm 12.8 \mathrm{ABC}$ & $0.1 \pm 0.1 \mathrm{~B}$ & $31.4 \pm 9.8 \mathrm{~A}$ & $0.0 \pm 0.0 \mathrm{C}$ \\
\hline Kill Strip (replaced) & Dichlorvos & $54.8 \pm 10.0 \mathrm{AB}$ & $38.7 \pm 8.0 \mathrm{ABC}$ & $0.1 \pm 0.2 \mathrm{~B}$ & $15.9 \pm 4.3 \mathrm{ABC}$ & $0.1 \pm 0.1 \mathrm{C}$ \\
\hline Kill Strip & Dichlorvos & $34.3 \pm 7.7 \mathrm{~B}$ & $22.3 \pm 5.5 \mathrm{BC}$ & $4.9 \pm 1.3 \mathrm{~B}$ & $6.3 \pm 1.8 \mathrm{BC}$ & $0.8 \pm 0.3 \mathrm{BC}$ \\
\hline Control & ------- & $31.3 \pm 6.4 \mathrm{~B}$ & $9.9 \pm 2.9 \mathrm{C}$ & $14.8 \pm 14.8 \mathrm{~A}$ & $4.1 \pm 1.2 \mathrm{C}$ & $2.5 \pm 0.6 \mathrm{~A}$ \\
\hline
\end{tabular}

Different letters within the same column indicate significant difference $(\alpha=0.05)$, Tukey's HSD.

Table 5. Comparison of dead and alive $H$. halys adults and nymphs with different insecticidal nettings in standard black pyramid traps

\begin{tabular}{lccrr}
\hline Active ingredient $(\%)$ & Trade name $(\mathrm{v} / \mathrm{v})$ & Dead adults & Live adults & Live nymphs \\
\hline Lambda-Cyhalothrin (22.8) & Warrior II (25\%) & $31.3 \pm 10.3 \mathrm{~A}$ & $0.8 \pm 0.4 \mathrm{~A}$ & $0.6 \pm 0.4 \mathrm{~ns}$ \\
Zeta-cypermethrin (3.75) + Bifenthrin (11.25) & Hero (25\%) & $20.9 \pm 5.6 \mathrm{AB}$ & $0.2 \pm 0.1 \mathrm{~A}$ & $0.3 \pm 0.1 \mathrm{~ns}$ \\
Zeta-cypermethrin (3.75) + Bifenthrin (11.25) & Hero (10\%) & $22.3 \pm 7.8 \mathrm{AB}$ & $0.9 \pm 0.6 \mathrm{~A}$ & $0.13 \pm 0.1 \mathrm{~ns}$ \\
Pyrethrins (1.40) & Pyganic (25\%) & $11.1 \pm 4.5 \mathrm{AB}$ & $10.1 \pm 2.7 \mathrm{~B}$ & $0.09 \pm 0.06 \mathrm{~ns}$ \\
Control & ------- & $9.5 \pm 2.5 \mathrm{~B}$ & $11.5 \pm 4.1 \mathrm{~B}$ & $0.8 \pm 0.6 \mathrm{~ns}$ \\
\hline
\end{tabular}

Different letters within the same column indicate significant difference $(\alpha=0.05)$, Tukey's HSD. Dead nymphs were not analyzed due to low captures. 


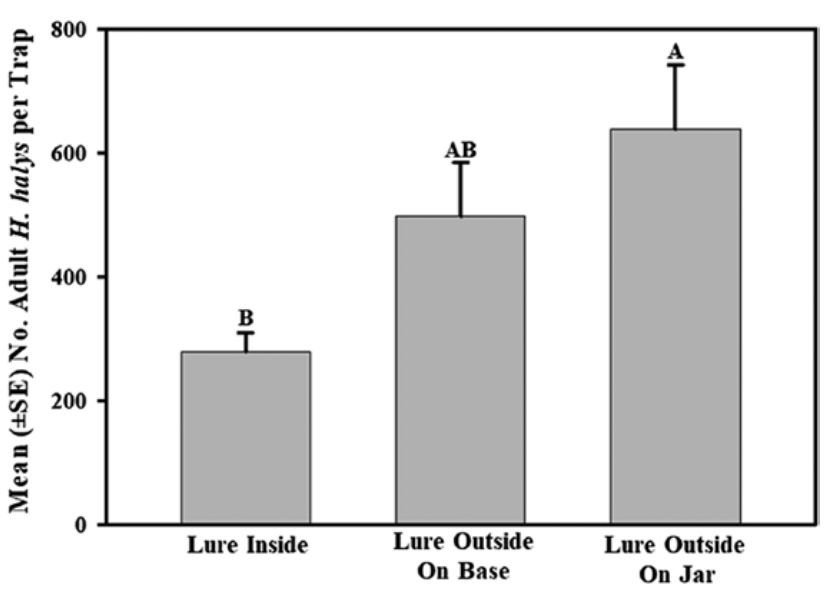

Fig. 4. Comparison of total $H$. halys mean captures in standard black pyramid traps with lures placed inside jar tops, outside on top of jar tops, and at the base of the pyramid. Bars with shared letters are not significantly different from each other ( $\alpha=0.05$, Tukey's HSD).

in traps. Recent research has used deltamethrin-impregnated netting successfully as a kill mechanism to capture over 1,000 H. halys adults during the overwintering and early spring period in pheromonebaited traps in heated buildings and in areas surrounding buildings (Morrison et al. 2017b). Comparisons among pyrethroid-impregnated netting showed that lambda-cyhalothrin was the only netting that killed more adult $H$. halys than control traps. Current killing mechanisms such as vapor tape need to be replaced several times throughout the growing season (Morrison et al. 2015), whereas insecticide impregnated netting effectively kills stink bugs (Kuhar et al. 2017), and remains effective throughout the season (Martin et al. 2007). However, all of these insecticide kill mechanisms (ear tags, vapor tape, insecticide netting) require insecticide registrations for their use. On the other hand, sticky traps do not require new registrations, and have been widely adopted to monitor for pest species in diverse systems including greenhouses (Heinz et al. 1992), stored products (Hagstrum et al. 1994), vegetable crops (Cho et al. 1995), and orchard crops (Boivin et al.1982, Hoddle et al. 2002).

Lure position on traps affected $H$. halys captures in our studies. Lures deployed on the outside of standard pyramid traps resulted in greater captures of $H$. halys compared to traps with lures inside collection jars in our studies. Lures positioned on the outside of traps likely increase the diffusion and plume reach of attractive semiochemicals as they are not confined in the small collection container with minimal air flow. Similar trends were observed in mosquito traps, with lures positioned on the outside of traps having greater captures than traps with lures on the inside (Ritchie et al. 2013). However, the optimal trap spacing or density is not known, but potentially could be resolved by quantifying the maximum dispersive distance of $H$. halys and plume reach of current lures, based on the methods developed by Miller et al. (2015). In preliminary trials using this methodology, traps baited with lures suggested that the trapping area of a single trap unit within a 12-h period was approximately 4.83 ha (Acebes-Doria, Rice and Leskey, unpublished data).

Overall, our results suggest that $H$. halys monitoring traps can be further improved to reduce cost and labor associated with deployment and maintenance. Although PHER + MDT have been proven to be attractive and reliable season-long stimuli for lures used in association with traps (Leskey et al. 2015), recent studies have identified ethyl $(2 E, 4 E, 6 Z)$-decatrienoate (EDT) as an additional attractant for $H$. halys that enhanced trap captures (Rice et al. 2018). Combining EDT with MDT and PHER may further increase trap captures and overall sensitivity of monitoring systems. Moreover, pyramid traps also augmented with light sources could further enhance trap captures (Rice et al. 2017). Future studies should focus on direct comparisons of standard pyramid traps with some of these simpler alternative trap designs under a range of $H$. halys densities and across a larger geographical area to determine whether they can provide reliable and less expensive tools for monitoring this invasive species.

\section{Acknowledgments}

We thank John Cullum, Tori Hancock, Brittany Poling, Kyle Bekelja, Nate Brandt, Mckenzie Allen, and Morgan Douglas for excellent technical assistance. This research was funded by USDA-NIFA Specialty Crop Research Initiative award \#2016-51181-25409.

\section{References Cited}

Aho, K. A. 2014. Foundational and applied statistics for biologists using R. CRC Press, Boca Raton, FL. pp. 596.

Aldrich, J. R., A. Khrimian, and M. J. Camp. 2007. Methyl 2,4,6-decatrienoates attract Stink bugs and tachinid parasitoids. J. Chem. Ecol. 33: 801-815.

American/Western Fruit Grower. 2011. Brown marmorated stink bug causes $\$ 37$ million in losses to mid-Atlantic apple growers. (http://www.growingproduce.com/article/21057/brown-marmorated-stink-bug-causes-37-millionin-losses-to-mid-atlantic-apple-growers) (accessed 9 August 2017).

Boivin, G., R. K. Stewart, and I. Rivard. 1982. Sticky traps for monitoring phytophagous mirids (Hemiptera: Miridae) in an apple orchard in southwestern Quebec. Environ. Entomol. 11: 1067-1070.

Cho, K., C. S. Eckel, J. F. Walgenbach, and G. G. Kennedy. 1995. Comparison of colored sticky traps for monitoring thrips populations (Thysanoptera: Thripidae) in staked tomato fields. J. Entomol. Sci. 30: 176-190.

Elton, C. S., 1958. The ecology of invasions by animals and plants. Methuen, London, UK.

Faúndez, E. I., and D. Rider. 2017. The brown marmorated stink bug Halyomorpha halys (Stål, 1855) (Heteroptera: Pentatomidae) in Chile. Arq Entomolóx xicos. 17: 305-307.

Gariepy, T. D., H. Fraser, and C. D. Scott-Dupreea. 2014. Brown marmorated stink bug (Hemiptera: Pentatomidae) in Canada: recent establishment, occurrence, and pest status in southern Ontario. Can. Entomol. 146: 579-582.

Hagstrum, D. W., A. K. Dowdy, and G. E. Lippert. 1994. Early detection of insects in stored wheat using sticky traps in bin headspace and prediction of infestation level. Environ. Entomol. 23: 1241-1244.

Heinz, K. M., M. P. Parrella, and J. P. Newman. 1992. Time-efficient use of yellow sticky traps in monitoring insect populations. J. Econ. Entomol. 85: 2263-2269.

Hoddle, M. S., L. Robinson, and D. Morgan. 2002. Attraction of thrips (Thysanoptera: Thripidae and Aeolothripidae) to colored sticky cards in a California avocado orchard. Crop Prot. 21: 383-388.

Hoebeke, E. R., and M. E. Carter. 2003. Halyomorpha halys (Stål) (Heteroptera: Pentatomidae): a polyphagous plant pest from Asia newly detected in North America. Proc. Entomol. Soc. Wash. 105: 225-237.

Hogmire, H. W. and T. C. Leskey. 2006. An improved trap for monitoring stink bugs in apple and peach orchards. J. Entomol. Sci. 41: 9-21

Joseph, S. V., J. C. Bergh, S. E. Wright, and T. C. Leskey. 2013. Factors affecting captures of brown marmorated stink bug, Halyomorpha halys (Hemiptera: Pentatomidae), in baited pyramid traps. J. Entomol. Sci. 48: 43-51.

Khrimian, A., P. W. Shearer, A. Zhang, G. C. Hamilton, and J. R. Aldrich. 2008. Field trapping of the invasive brown marmorated stink bug, Halyomorpha halys, with geometric isomers of methyl 2,4,6- decatrienoate. J. Agric. Food Chem. 56: 196-203.

Khrimian, A., A. Zhang, D. C. Weber, H. Y. Ho, J. R. Aldrich, K. E. Vermillion, M. A. Siegler, S. Shirali, F. Guzman, and T. C. Leskey. 2014. Discovery of the aggregation pheromone of the brown marmorated stink bug (Halyomorpha halys) through the creation of stereoisomeric libraries of 1-bisabolen-3-ols. J. Nat. Prod. 77: 1708-1717. 
Kuhar, T. P., B. D. Short, G. Krawczyk, and T. C. Leskey. 2017. Deltamethrinincorporated nets as an integrated pest management tool for the invasive Halyomorpha halys (Hemiptera: Pentatomidae). J. Econ. Entomol. 110: 543-545.

Lee, D. H., and T. C. Leskey. 2015. Flight behavior of foraging and overwintering brown marmorated stink bug, Halyomorpha halys (Hemiptera: Pentatomidae). Bull. Entomol. Res. 105: 566-573.

Lee, K. C., C. H. Kang, D. W. Lee, S. M. Lee, C. G. Park, and H. Y. Choo. 2002. Seasonal occurrence trends of hemipteran bug pests monitored by mercury light and aggregation pheromone traps in sweet persimmon orchards. Korean J. Appl. Entomol. 41: 233-238.

Lee, D-H, A. L. Nielsen and T. C. Leskey. 2014. Dispersal capacity and behavior of nymphal stages of Halyomorpha halys (Hemiptera: Pentatomidae) evaluated under laboratory and field conditions. J. Insect Behav. 27: 639-651.

Leskey, T. C., and H. W. Hogmire. 2005. Monitoring stink bugs (Hemiptera: Pentatomidae) in mid-Atlantic apple and peach orchards. J. Econ. Entomol. 98: 143-153.

Leskey, T. C., and A. L. Nielsen. 2018. Impact of the invasive brown marmorated stink bug in North America and Europe: history, biology, ecology, and management. Annu. Rev. Entomol. 63: 599-618.

Leskey, T. C., S. E. Wright, B. D. Short, and A. Khrimian. 2012a. Development of behaviorally-based monitoring tools for the brown marmorated stink bug (Heteroptera: Pentatomidae) in commercial tree fruit orchards. J. Entomol. Sci. 47: 76-85.

Leskey, T. C., B. D. Short, B. B. Butler and S. E. Wright. 2012b. Impact of the invasive brown marmorated stink bug, Halyomorpha halys (Stål) in midAtlantic tree fruit orchards in the United States: case studies of commercial management. Psyche.

Leskey, T. C., A. Agnello, J. C. Bergh, G. P. Dively, G. C. Hamilton, P. Jentsch, A. Khrimian, G. Krawczyk, T. P. Kuhar, D-H. Lee, et al. 2015. Attraction of the invasive Halyomorpha halys (Hemiptera:Pentatomidae) to traps baited with semiochemical stimuli across the United States. Environ. Entomol. 44: 746-756.

Lockwood, J. L., M. F. Hoopes, and M. P. Marchetti. 2013. Invasion ecology. Blackwell Publishing, Malden, MA.

Martin, T., F. Chandre, J. Chabi, P. F. Guillet, M. Akogbeto, and J. M. Hougard. 2007. A biological test to quantify pyrethroid in impregnated nets. Trop. Med. Int. Health. 12: 245-250.

Miller, J. R., C. G. Adams, P. A. Weston, and J. H. Schenker. 2015. Trapping of small organisms moving randomly: principles and applications to pest monitoring and management. Springer, New York, NY.

Morrison, W. R., 3rd, J. P. Cullum, and T. C. Leskey. 2015. Evaluation of trap designs and deployment strategies for capturing halyomorpha halys (Hemiptera: Pentatomidae). j. Econ. Entomol. 108: 1683-1692.

Morrison, W. R., 3rd, P. Milonas, D. E. Kapantaidaki, M. Cesari, E. Di Bella, R. Guidetti, T. Haye, L. Maistrello, S. T. Moraglio, L. Piemontese, et al. 2017a. Attraction of Halyomorpha halys (Hemiptera: Pentatomidae) haplotypes in North America and Europe to baited traps. Sci. Rep. 7: 16941.

Morrison, W. R., 3rd, A. Acebes-Doria, E. Ogburn, T. P. Kuhar, J. F. Walgenbach, J. C. Bergh, L. Nottingham, A. Dimeglio, P. Hipkins, and T. C. Leskey. 2017b. Behavioral response of the brown marmorated stink bug (Hemiptera: Pentatomidae) to semiochemicals deployed inside and outside anthropogenic structures during the overwintering period. J. Econ. Entomol. 110: 1002-1009.

Nielsen, A. L., K. Holmstrom, G. C. Hamilton, J. Cambridge, and J. IngersonMahar. 2013. Use of black light traps to monitor the abundance, spread, and flight behavior of Halyomorpha halys (Hemiptera: Pentatomidae). J. Econ. Entomol. 106: 1495-1502.

Ragsdale, D. W., B. P. McCornack, R. C. Venette, B. D. Potter, I. V. MacRae, E. W. Hodgson, M. E. O’Neal, K. D. Johnson, R. J. O’Neil, C. D. DiFonzo, et al. 2007. Economic threshold for soybean aphid (Hemiptera: Aphididae). J. Econ. Entomol. 100: 1258-1267.

Rice, K. B., C. J. Bergh, E. J. Bergmann, D. J. Biddinger, C. Dieckhoff, G. P. Dively, H. Fraser, T. D. Gariepy, G. C. Hamilton, T. Haye, et al. 2014. Biology, ecology and management of brown marmorated stink bug (Halyomorpha halys). J. Integ. Pest Manag. 5: 1-13.

Rice, K. B., S. J. Fleischer, C. M. De Moraes, M. C. Mescher, J. F. Tooker, and M. Gish. 2015. Handheld lasers allow efficient detection of fluorescent marked organisms in the field. Plos One. 10: e0129175.

Rice, K. B., J. P. Cullum, N. G. Wiman, R. Hilton, and T. C. Leskey. 2017. Halyomorpha halys (Hemiptera: Pentatomidae) response to pyramid traps baited with attractive light and pheromonal stimuli. Florida Entomol. 100: 449-453.

Rice, K. B., R. H. Bedoukian, G. C. Hamilton, P. Jentsch, A. Khrimian, P. MacLean, W. R. Morrison, 3rd, B. D. Short, P. Shrewsbury, D. C. Weber, et al. 2018. Enhanced response of halyomorpha halys (Hemiptera: Pentatomidae) to its aggregation pheromone with ethyl decatrienoate. J. Econ. Entomol. 111: 495-499.

Ritchie, S. A., G. Cortis, C. Paton, M. Townsend, D. Shroyer, P. Zborowski, S. Hall-Mendelin, and A. F. Van Den Hurk. 2013. A simple non-powered passive trap for the collection of mosquitoes for arbovirus surveillance. J. Med. Entomol. 50: 185-194.

SAS Institute. 2004. SAS, version 9.1. SAS Institute, Cary, NC.

Short, B. D., A. Khrimian, and T. C. Leskey. 2017. Pheromone-based decision support tools for management of Halyomorpha halys in apple orchards: development of a trap-based treatment threshold. J. Pest Sci. 90: 1191-1204.

Szczepaniec, A., S. F. Creary, K. L. Laskowski, J. P. Nyrop, and M. J. Raupp. 2011. Neonicotinoid insecticide imidacloprid causes outbreaks of spider mites on elm trees in urban landscapes. Plos One. 6: e20018.

Tada, N., M. Yoshida, and Y. Sato. 2001a. Monitoring of forecasting for stink bugs in apple 1. Characteristics of attraction to aggregation pheromone in Iwate Prefecture. Annual Report of Plant Protection of North Japan. 52: 224-226.

Tada, N., M. Yoshida, and Y. Sato. 2001b. Monitoring of forecasting for stink bugs in apple 2 . The possibility of forecasting with aggregation pheromone. Annual Report of Plant Protection of North Japan. 52: 227-229.

Toscano, N. C., A. J. Mueller, V. Sevacherian, K. Sharma, T. Nulus, and H. T. Reynolds. 1974. Insecticide applications based on hexalure ${ }^{\circledR}$ trap catches versus automatic schedule treatments for pink bollworm moth control. J. Econ. Entomol. 67: 522-524.

Toyama, M., H. Kishimoto, K. Mishiro, R. Nakano, and F. Ihara. 2015. Sticky traps baited with synthetic aggregation pheromone predict fruit orchard infestations of Plautia stali (Hemiptera: Pentatomidae). J. Econ. Entomol. 108: 2366-2372.

Weber, D. C., T. C. Leskey, G. C. Walsh, and A. Khrimian. 2014. Synergy of aggregation pheromone with methyl (E,E,Z) -2,4,6-decatrienoate in attraction of Halyomorpha halys (Hemiptera: Pentatomidae). J. Econ. Entomol. 107: 1061-1068.

Wermelinger, B., D. Wyniger, and B. Forster. 2008. First records of an invasive bug in Europe: Halyomorpha halys Stal (Heteroptera: Pentatomidae), a new pest on woody ornamentals and fruit trees? Mitt Schweiz Entomol Ges. 81: 1-8. 